Brit. J. vener. Dis. (1956), 32, 207.

\title{
EDITORIAL
}

\section{VENEREOLOGY IN TRANSITION}

Whither is the venereologist going? This important question was posed by Dr. Earle Moore (p. 217) of Johns Hopkins Hospital when he addressed the Medical Society for the Study of Venereal Diseases at its recent meeting at Oxford. In the U.S.A., venereology really means syphilology, and the clinical work has been done largely on a part-time basis by interested physicians who also actively practise another speciality, e.g., internal medicine, dermatology, or neuropsychiatry. With the declining incidence of syphilis in the U.S.A. and the reduction in financial grants, the syphilologist has applied himself more and more to his other interest; for him transition has been relatively easy and it has not given rise to serious administrative or financial difficulty. Dr. Moore compared the syphilologist of 1956 to a fighter pilot who, his aircraft having been shot from under him, is parachuting down and wondering how this came about and what he will do when he lands. Dr. Moore himself has made a happy landing on the broad and fertile field of chronic diseases, and his investigations of cases, giving chronic biologic false positive reactions to the standard serological tests for syphilis, suggests that this laboratory phenomenon may detect early the potential candidate for later systemic lupus erythematosus and other collagen vascular disturbances. These studies have been made possible by the development of the Treponemal Immobilization test and more readily available facilities for this test are urgently required in Britain.

As pointed out in the Discussion (p. 224), the position in Great Britain is fundamentally different. Here venereology is a comprehensive speciality in its own right and is recognized as such in the National Health Service; it is practised by the majority on a full-time basis and has hitherto been regarded as a permanent career. Transition in the employment of the professional skill and experience of the British venereologist, if it were to become necessary, might well provide greater administrative problems than has been the case in the U.S.A. Dr. Moore has drawn attention to the broad training and knowledge re- quired by the syphilologist embracing internal medicine, dermatology, ophthalmology, pathology, neuropsychiatry, immunology, chemotherapy, epidemiology, and public health, and the British venereologist must also be acquainted with the relevant parts of urology, gynaecology, and paediatrics. If and when transition becomes necessary for the venereologist, his comprehensive skills and interests must be found suitable scope within the National Health Service.

However, the need for this transition has not yet arrived in Britain. While early syphilis has greatly declined it has not entirely disappeared; small outbreaks arise sporadically in the provincial areas and cases still occur regularly in the major cities and seaports. The incidence of late syphilis has only recently commenced to decline and cases missed in the past still await discovery and treatment. Gonorrhoea is common in the larger towns and the number of infections treated in the clinics has increased; concern has recently been expressed by the gynaecologists of a large city at the marked increase in admissions of young women with acute salpingitis. Non-gonococcal urethritis presents diagnostic and therapeutic difficulty, and it causes the individual much anxiety if not physical disability. Its incidence rises relatively as gonococcal infections diminish and, the more successful the control of gonorrhoea, the greater becomes the importance of non-gonococcal urethritis. Trichomonas vaginalis infection in women is widespread and causes much disability and suffering, whilst its role in the male is gaining increasing attention; an effective remedy still eludes discovery although perhaps developments in systemic therapy may provide the answer. The need for liaison between gynaecologist and venereologist in the management of women infected with $T$. vaginalis and of their male consorts, recommended previously in an Editorial in this Journal (1954), still remains. Recent investigations by King and his colleagues ( $p$. 209) have revealed that more patients at the Whitechapel Clinic, London, present evidence of infection with lymphogranuloma venereum than one would 
have expected, and there have been recent reminders that yaws (Laird, 1955) and granuloma inguinale (Knight and Fowler, 1956) may also require to be considered in differential diagnosis. The valuable work of surveillance and reassurance of those exposed to risk of infection, carried out in the V.D. Clinics, continues unabated.

It is apparent that significant trends requiring a change of emphasis are taking place and in this respect venereology in Britain is indeed in transition.
But the speciality retains its interest and problems and the number of people seeking advice continues undiminished. The venereologist in Britain still remains airborne and has the enemy in his sights; his parachute is not needed yet!

\section{REFERENCES}

British Journal of Venereal Diseases (1954). 30, 123.

Knight, G. H., and Fowler, W. (1956). Brit. med. J., 2, 980

Laird, S. M. (1955). British Journal of Venereal Diseases, 31, 30. 